\title{
The Analysis of the Investment Climate in China after the Financial Crisis
}

\author{
Yuhong Cheng, Jing Lu \\ School of Economics, Jinan University, Guangzhou, China \\ Email:ngslujing@163.com
}

Received 17 November 2015; accepted 26 December 2015; published 29 December 2015

Copyright (C) 2015 by authors and Scientific Research Publishing Inc.

This work is licensed under the Creative Commons Attribution International License (CC BY). http://creativecommons.org/licenses/by/4.0/

c) (i) Open Access

\begin{abstract}
Is Chinese investment climate worse off after the financial crisis? Has the investment climate structure in China changed? Based on these two questions, by comparing the investment situation between 2007 and 2013 in different provinces and cities, the paper uses principal component analysis and cluster analysis from province, cluster and region perspectives to study the regional investment climate changes in China after the financial crisis. The study shows that after the financial crisis the general investment climate does not have huge changes. The east, middle, and west regions have significant differences, among which there is better investment climate in the east region, the evolvement in the middle region is distinct, whilst the improvement from the west region is less. This paper also gives a few political suggestions towards the results.
\end{abstract}

\section{Keywords}

Investment Climate, FDI, Principal Component Analysis, Clustering Analysis

\section{Introduction}

Reviewing on the global economic development in 2013 shows that the increase rate of global economy has not met anticipation of the circles concerned due to impact of geopolitics, natural disasters and different risk events. Instead, the economy is further slowed down. Looking around the world, you will find China is a world apart obviously. China domestic economy has good environment, with economical operation basically keeping a state of low increase and low inflation. But in fact there are a good many problems hidden behind the good scene. From January to December in 2013, the foreign direct investment (FDI) was 111.72 billion dollars, falling by $3.7 \%$ on a year-on-year level, the first annual dropping since 2009. Despite that the influx of FDI decreased for consecutive months, the investment amount of foreign enterprises in China in 2013 was still as high as 100 billion dollars. In 2013, China became a less developed country with the most FDI for the 21st year consecutively, 
which seemed to show that the multinationals were still very confident in China's investment climate.

Besides, the investment climates in Chinese provinces and cities have presented a splitting state of two groups. The first group tends to be east provinces. The paper will make a system evaluation on Chinese investment climate through principal component analysis and cluster analysis from three perspectives of province, clustering and region, and analyze its change, in an effort to answer the following two questions: Is China's investment climate worse off after the financial crisis? Has the investment climate structure in China changed?

\section{Literature Review}

The evaluation studies on investment climate began in the 1960s with influential researcher such as Bunting and Storper and so on. The regional economics, industrial economics and other allied disciplines began to set foot in the field with improvement of importance of investment climate appraisal. The foreign research mostly emphasizes particularly on taking country as object to compare the countries. The typical research techniques are "cold and hot analysis" which is a static comparison. This method is put forward by Yithes Teriphac and Peter Bunting, Roche grade scoring put forward by Storper and dynamic analysis method for investment climate put forward by American Dow Chemical Company.

While domestic research on investment climate started late. The research fans out gradually with empirical analysis on investment climates of different regions, and more focuses on appraisal over investment climate. The analytic hierarchy process, principal component analysis, grey association degree analytical method and so on are utilized to evaluate advantages and disadvantages of investment climates by comparing comprehensive scores of different cities or regions in the indices. Cheng (1995) [1] uses entropy theory to discuss entropic state characteristics and ripening styles of city investment climates in China, based on which puts forwards several measures to perfect city investment climate. Pan (2007) [2] establishes a system of regional investment climate assessment index from natural environment, infrastructure, economic environment, market environment and political environments. The 31 domestic provinces, cities and regions are taken as study object and SPSS software is used to make principal component analysis of 43 indices in assessment index system, and then cluster analysis is made on this basis. Finally an evaluation is obtained for cluster analysis result.

In the meanwhile, a great many scholars proceed with one certain foreign capital source to make area-delimited analysis on investment climates in different regions in China and a microanalysis on general investment climate in China. Duan (2006) [3] makes an analysis on the regional environment for Taiwan merchants to invest in the mainland, puts forward new regional preference of Taiwan merchants for mainland investment climate, and points out that Taiwan merchants' investment approaches saturation in South China, instead they favor more second-tier cities in east China, gradually focus on key cities in inland regions. The north China is further an up-and-coming star for attracting Taiwan merchants. Liu (2012) [4] lays stress on research on recent advance and new trend of direct investment by Japan in China, and puts forward pertinent policy advice.

With gradual deepening of reform and opening and financial crisis in 2008, domestic research on investment climate began to focus on vertical analysis. Zhou (2013) [5] lays stress on research on the investment climate change in Pearl River Delta since the reform and opening. The analytic hierarchy process is used after survey of 56 enterprises in the delta to study the change of investment climates for labor concentrated industries and technology intensive industries there and points out that change of investment climate are different for different industries. Ma (2014) [6] analyzes the investment climate since 2004-2013 and explains that the whole investment climate in China is not worse off.

In China, different levels of organizations adopt assorted means to assess investment climate apart from scholars' study. In 2006, the World Bank [7] initiated a three-year survey for 12,400 enterprises in 120 cities in China, and issued an appraisal report titled "Government governance, investment climate and harmonious society-improvement of competitive power in 120 cities in China". The general way of thinking in this report is to combine two single performance evaluation indices - total factor productivity (TFP) and foreign direct investment (FDI) with various investment climates factors put forward by world bank, and score and rank the investment climate for domestic fund and investment climate for foreign capital in 120 cities through calculating impact of various investment factors involving domestic funded enterprises and the impact of various investment factors involving foreign enterprises.

For business organizations, taking TEEMA [8] as an example, it analyzed comprehensive ranking of the competitive power of mainland investment climate, and figure out score of comprehensive investment climate of 
cities according to the survey and findings from the four parts of general competitive power analysis of city, evaluation of mainland investment climate, evaluation of investment risk in mainland, recommendation degree of Taiwan merchants.

The provincial governments also introduced a great many investment climate appraisals and examinations in the hope of improving investment climate in the province. Taking Fujian and Jiangxi as two examples, the analytical framework and main theoretical hypothesis used by investment climate appraisal there are significantly different. Fujian is oriented towards environment demand of foreign enterprise investment, uses theory of satisfaction over enterprise investment climate to evaluate the investment climates in cities and regions of the provinces (Chen Jing 2009) [9]; while Jiangxi takes comprehensive environment theory as the main analytical framework, and divides the provincial administrative area investment climate into natural environment, economic development level, infrastructure and social service environment, then put forwards indices of two and three levels for the four environments to reflect general development of vertical investment climate there and rank of Jiangxi's investment climate in 11 provinces in middle and east part of China based on calculation, synthesizing and contrasting of vertical annual data in Jiangxi and horizontal data of provinces in the same year (Wang, 2010) [10].

Generally speaking, Chinese research on investment climate is mainly about applicability, with most of them being static evaluation, especially that the research on comparison of change of investment climate dynamic in provinces and cities in recent years is less. With financial crisis in 2008 as the breakpoint, the paper combines three perspectives of province, clustering and region to construct index system to analyze the investment climate in provinces and cities in 2007 and 2013, make contrastive analysis on change of investment climate, judge and find out the impact of financial crisis on three regional investment climate in China.

\section{The Evaluation and the Features of Change in the Provincial Investment Climate}

\subsection{Evaluation Indices and Methods}

With predecessors' research on investment climate indices analytical model as reference, and according to the author's knowledge and data availability, the paper selects 37 representative indices closely related to investment climate and builds up a system of regional investment climate evaluating indicator ${ }^{1}$ (Table 1) after combining physical circumstances of provinces, cities and municipalities, considering the correlation between subsystems in the quota system, and repeated screening and correlation studies. To be specific, the regional investment climate evaluating indicator system constructed in the paper is divided into general objective, appraisal of comprehensive layer, appraisal of project layer and appraisal of factor layer.

For the layer of general objective investment climate, the system covers five subsystems of resource environment, economic environment, market environment, infrastructure and social environment, describes and measures the advantages and disadvantages of investment climate in domestic provinces, cities and regions from the appraisal of factor layer composed of 37 statistical indices of 21 project layers.

\subsection{Evaluation Results}

This paper adopts principal component analysis to progressively synthesize upward the four-level regional investment climate evaluating indicator system constructed above, and determines weight coefficient of indices' composite function at different levels, thereby constructing measurement model of each level of indices. There into, the principal constituent is extracted from the five subsystems obtained above in the principal component analysis on general objective level. The paper extracts one principal constituent, and accumulative contribution rate is $78.465 \%$, and this variance contribution rate is taken as weight to get comprehensive score of investment climates in provinces and cities. The formula is: $\mathrm{Z}=0.78465 \mathrm{~F} 1$ ( $\mathrm{Z}$ means composite index of regional investment climate; $\mathrm{F}$ is the score of principle constituent.)

\footnotetext{
${ }^{1}$ What needs clarification is that investment climate appraisal generally include soft and hard indices. The former ones include political stability, law healthiness degree, government and citizens' attitude towards foreign investment. The factors having major influence on investment are mainly political and law environment. For China, due to small differences of politics and law in different regions, even there are differences in law enforcement justice in regions, they are difficult to be quantified. Thus to reduce subjective randomness, the paper mainly utilizes hard indices for objective appraisal.
} 
Table 1. Regional investment climate evaluation index system.

\begin{tabular}{|c|c|c|c|}
\hline Objective & $\begin{array}{l}\text { Comprehensive } \\
\text { level }\end{array}$ & Project level & Factor level \\
\hline \multirow{17}{*}{ 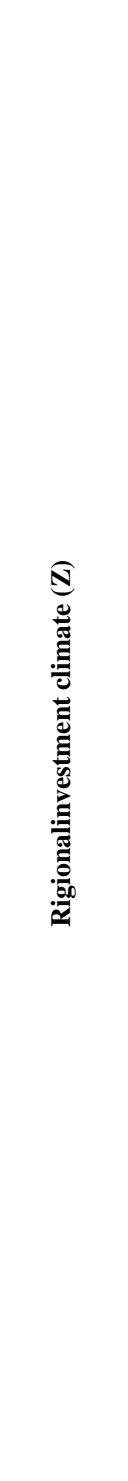 } & \multirow{5}{*}{$\begin{array}{c}(\mathrm{Z} 1) \\
\text { resource } \\
\text { environment }\end{array}$} & $\begin{array}{l}\mathrm{Z11} \\
\text { natural resources } \\
\text { conditions }\end{array}$ & Per capita arable area; per capita water resources \\
\hline & & $\begin{array}{c}\mathrm{Z12} \\
\text { ecological environment }\end{array}$ & $\begin{array}{l}\text { Forest coverage rate; comprehensive } \\
\text { utilization rate of industrial solid wastes }\end{array}$ \\
\hline & & $\begin{array}{c}\mathrm{Z} 21 \\
\text { labor \& capital }\end{array}$ & $\begin{array}{l}\text { Population between } 15 \text { and 65; } \\
\text { per capita bank savings; per capita capital }\end{array}$ \\
\hline & & $\begin{array}{c}\mathrm{Z22} \\
\text { technological level }\end{array}$ & Expenditure of R\&D; the ratio of R\&D and GDP \\
\hline & & $\begin{array}{c}\mathrm{Z23} \\
\text { economic level }\end{array}$ & Per capita GDP; per capita fixed assets \\
\hline & \multirow[t]{4}{*}{$\begin{array}{l}\text { (Z2) economic } \\
\text { environment }\end{array}$} & $\begin{array}{c}\mathrm{Z24} \\
\text { urbanization level }\end{array}$ & $\begin{array}{l}\text { Proportion of urban residents; urban } \\
\text { water supply pervasion; urban per capita road area; Per million } \\
\text { people public transport vehicles }\end{array}$ \\
\hline & & $\begin{array}{c}\text { Z25 } \\
\text { size of the economy }\end{array}$ & GDP; gross capital formation The total fixed assets \\
\hline & & $\begin{array}{c}\text { Z26 } \\
\text { economic structure }\end{array}$ & $\begin{array}{l}\text { The proportion of secondary industry employment; The } \\
\text { proportion of the tertiary industry employment }\end{array}$ \\
\hline & & $\begin{array}{l}\mathrm{Z27} \\
\text { inflation rate }\end{array}$ & CPI \\
\hline & \multirow{2}{*}{$\begin{array}{l}\text { (Z3) } \\
\text { market } \\
\text { environment }\end{array}$} & $\begin{array}{c}\text { Z31 } \\
\text { market size }\end{array}$ & $\begin{array}{c}\text { Total population; total retail sales of consumer goods; Consumer } \\
\text { spending level }\end{array}$ \\
\hline & & $\begin{array}{c}\text { Z32 } \\
\text { Opening up }\end{array}$ & Import and export volume/GDP \\
\hline & \multirow{2}{*}{$\begin{array}{l}\mathbf{( Z 4 )} \\
\text { infrastructures }\end{array}$} & $\begin{array}{l}\mathrm{Z41} \\
\text { transportation conditions }\end{array}$ & $\begin{array}{l}\text { Land transportation freight volume; water transportation } \\
\text { employee; air transportation employee }\end{array}$ \\
\hline & & $\begin{array}{c}\mathrm{Z42} \\
\text { Information level }\end{array}$ & Per capita telephone service traffic; Internet penetration rate \\
\hline & \multirow{4}{*}{$\begin{array}{l}\text { (Z5) } \\
\text { social } \\
\text { environment }\end{array}$} & $\begin{array}{l}\mathrm{Z51} \\
\text { quality of life }\end{array}$ & Market environment, infrastructures and social environment \\
\hline & & $\begin{array}{c}\text { Z52 } \\
\text { social services }\end{array}$ & Per capita retail sales of social consumption goods \\
\hline & & $\begin{array}{c}\text { Z53 } \\
\text { education }\end{array}$ & $\begin{array}{l}\text { The average number of students per one hundred thousand people } \\
\text { in Senior High School; } \\
\text { The average number of students per one hundred thousand people } \\
\text { in colleges and universities; }\end{array}$ \\
\hline & & $\begin{array}{c}\mathrm{Z54} \\
\text { social equity }\end{array}$ & Urban and rural Consumption level index \\
\hline
\end{tabular}

For the comprehensive evaluation values have both the positive and negative ones, the paper adopts matrix equidistance geometric proportion transformation for data processing in an effort to increase intuitiveness to facilitate analysis. The transformed comprehensive evaluation value and rank are as shown in table ${ }^{2}$. What needs explanation is that due to data accessibility, the Tibet data in 2007 is not complete, thus the data analysis on investment climate has to delist Tibet. The source of the data in the paper is China statistical yearbook 2008 and 2013, and other correlated data provided by state Statistics Department.

\subsection{Change Features}

1) The difference between the east, middle, and west regions has increased and no sign of easing nationally.

2) Regardless year 2007 or 2013, there are fault phenomenon in the investment climate of the national provinc-

${ }^{2} B=A+\left(1-A_{\min }\right) ; C=B \times\left(100 / B_{\max }\right)$, in which, $A$ is the vector for the row of original scores, $B$ is the vector for conversion row, $C$ is the vector for transformation target row, $A_{\min }$ is the minimum element of $A$, and $B_{\max }$ is the maximum element of $B$. 
es (cities, districts). For instance, in 2007, the first and the second is Beijing and Shanghai, with 11 points gap, while there is 8 points difference between the $9^{\text {th }}$ ranking Liaoning and $10^{\text {th }}$ ranking Hebei. In 2013, the fault situation was not eased but even deteriorated, the first two provinces were Guangdong and Jiangsu but with 15 points difference and there was 14 points gap between the $6^{\text {th }}$ position Shanghai and the $7^{\text {th }}$ position Fujian.

3) There were significant changes of the rankings regarding some provinces and some middle and west provinces were outstanding. Shandong, Henan, Anhui, Guangxi, Shanxi, Guizhou went up for more than 3 seats. Among them Anhui improved the most with 11 seats increase and Shanxi had 7 seats increase. Several provinces (including cities, districts) went more than 3 seats backwards: Beijing, Shanghai, Hebei, Hubei, Shanxi, Inner Mongolia, Jilin, Xinjiang.

4) Among 4 municipalities, Beijing, Shanghai and Tianjin went downwards. Chongqing stood in the middle ranking with not much deviation.

\section{Cluster Analysis of Investment Climate of Chinese Provinces and Cities}

In order to determine the inside similarities and differences of the investment climate of different provinces and cities in China, we plan to use cluster analysis method to classify the regional investment climate. We take the original scores of investment resource environment in 2013 and 2007 and the scores from the 5 sub-systems as the raw data for the cluster analysis conduct cluster computing with Euclidean square distance between measure groups via SPSS 19.0. The cluster analysis results (Figure 1 and Figure 2) are presented in the following:

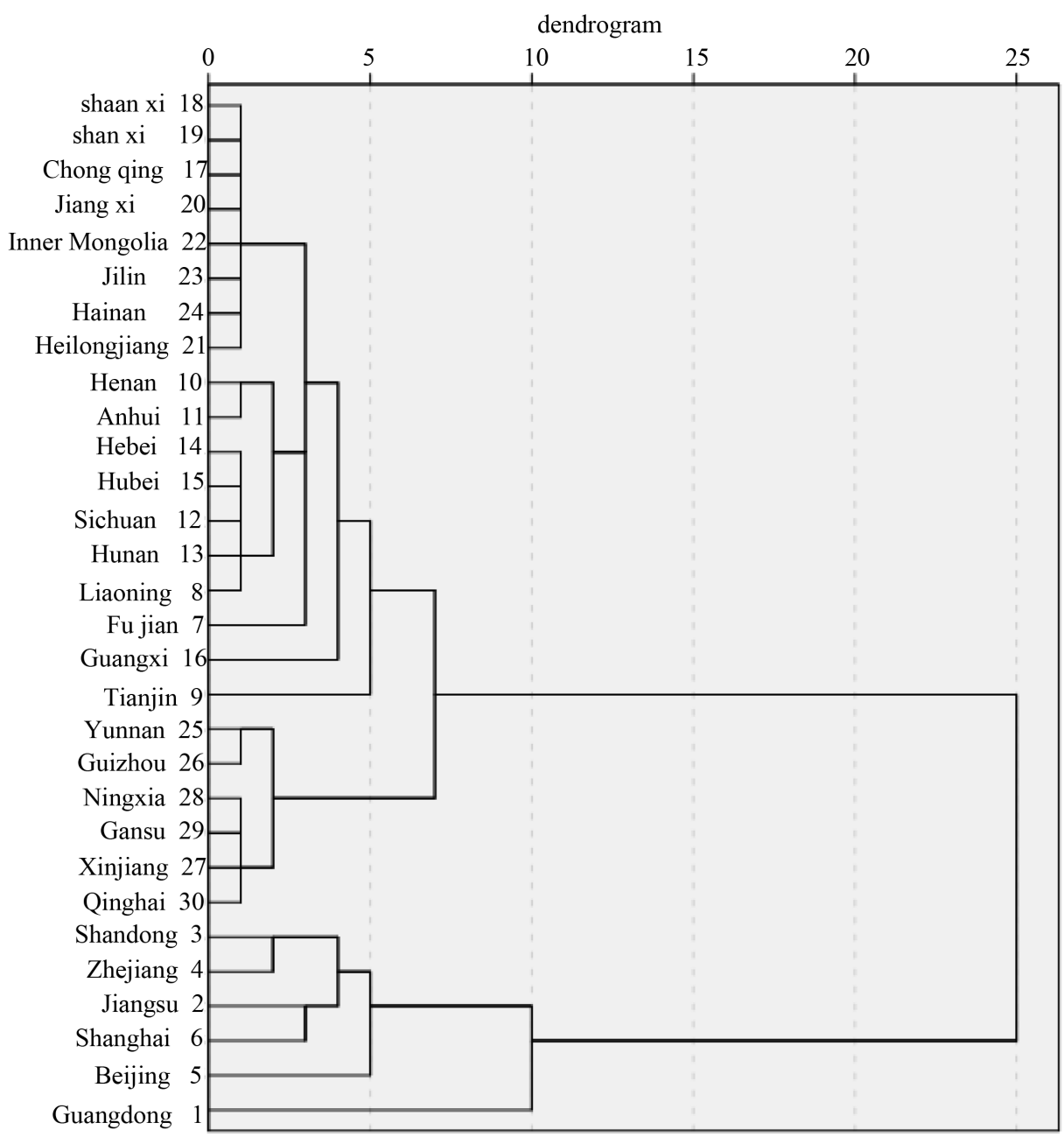

Figure 1. Clustering analysis of China’s investment climate at provincial level in year 2013. 


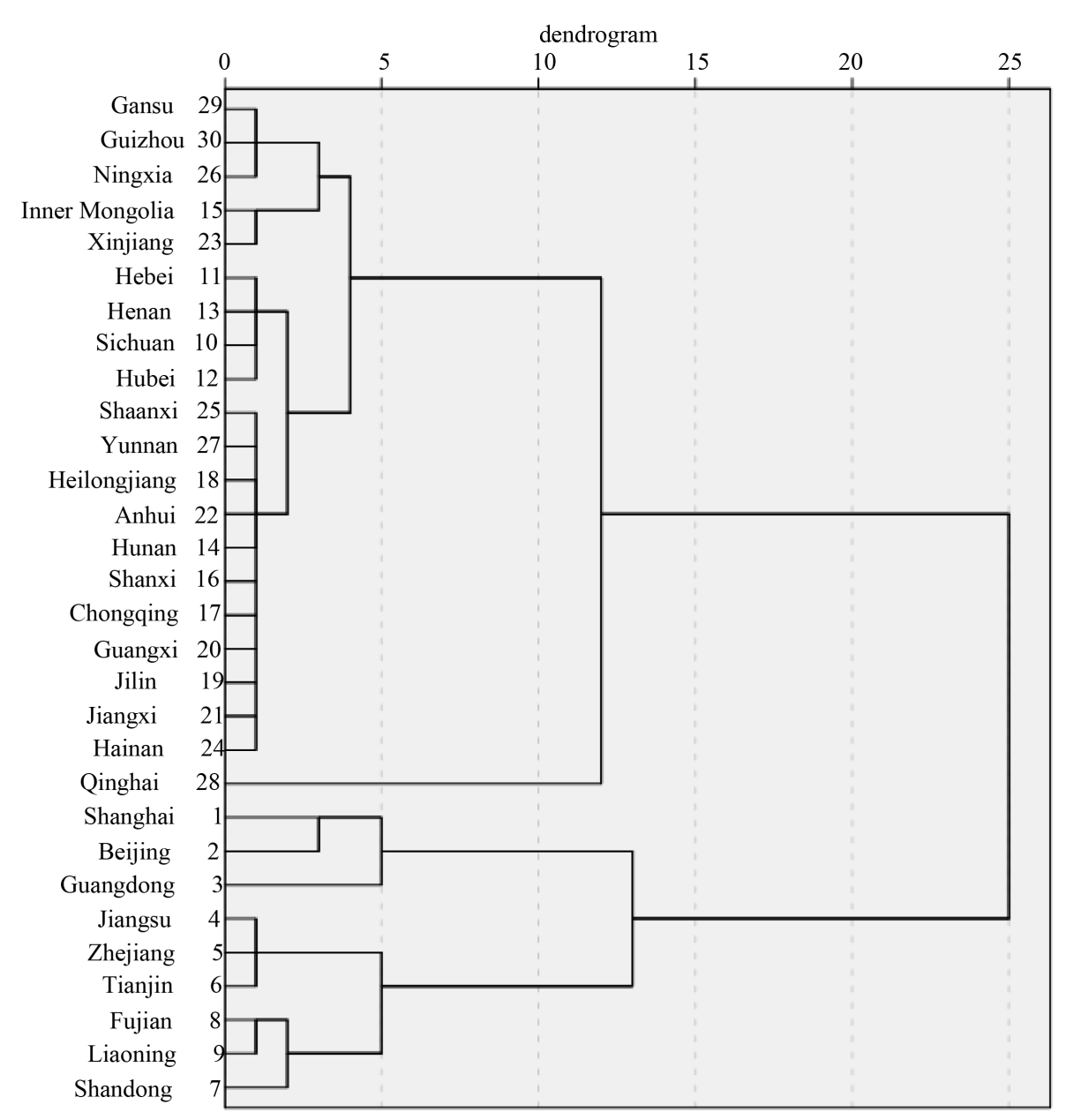

Figure 2. Clustering analysis of China’s investment climate at provincial level in year 2007.

\subsection{Similarities of the Clusters}

1) The overall pattern of the same 2013 clustering is generally comparable with 2007, both with 2 distinct groups.

2) The cluster is closely linked to regional economic development. Compare to the Midwest regions, the East has good economic foundation. First group is always formed by the eastern provinces, and the Central and Western provinces are in the second group.

3) There are some similarities between the same regional provinces. Clustering tree diagram clearly shows that provinces can be classified in the same region quickly. As shown in Figure 1, 2013investment climate of Central composite scored for 10th and 11th in Henan, Anhui and Zhejiang in the East (4), Shandong (3), as well as 2007 and 2013 of Western provinces such as Gansu, Guizhou, Ningxia.

4) There is some degree of relevance between the investment climate ranking and clustering of provinces. Generally speaking, provinces with closer rankings tend to fall into the same category. In Figure 1, Shaanxi (18), Shanxi (19), Chongqing (17), Jiangxi (20), Inner Mongolia (22), Jilin (23), Heilongjiang (21) and Hainan (24) to class soon; in Figure 2, Hebei (11), Henan (13), Sichuan (10) and Hubei (12).

\subsection{The Changes of the Clusters}

1) The decreased members of the first group, Tianjin, Liaoning and Fujian joined the second group. As far as the first group itself, there is internal changes in the cluster. The original "Beijing, Shanghai and Guangzhou" cluster no longer exists. Guangdong and Beijing form its own group, Shanghai and Jiangsu form one class; just as "Jiangsu and Zhejiang provinces” cluster changes to "Shandong and Zhejiang” cluster. 
2) For 2013 the clustering situation within the second group more complex and diverse than 2007. In 2013, the cluster in the second group is no longer constituted by the majority of Western provinces with indiscrimination but a significanthierarchy. Fujian, Guangxi excelled because of its resources and environment, form a group. Tianjin clustered later with other provinces. On the economic and social environment, Tianjin is the leader in the second group, but its weakness is on the low environmental performance. At the same time, infrastructure, market conditions seem to be mediocrity in the mid-west under the background of rapid development.

In the second group, there was a panel of top 4 provinces “leading momentum of development” group in 2007 and in 2013, the group number expanded to 7, new members mainly from the central provinces. The group generated divisions, Henan and Anhui province are the leader in central provinces in terms of resource environment, economic environment and infrastructure and team up fast. Another team consists of Hebei, Liaoning, Sichuan, Hubei, and Hunan.

The second team was formed by Shaanxi, Yunnan, Heilongjiang, Anhui, Hunan, Shanxi, Chongqing, Guangxi, Jilin, and Jiangxi but the members reduced. By grasping development opportunities from 2007 to 2013, the gap appeared in terms of five main subsystems. Anhui, Hunan developed relatively well and entered a "momentum leading” team and Yunnan went back to the less developed team with other west provinces.

\section{Dynamic Regional Change Analysis of Investment Climate of Chinese Provinces and Cities}

Since Reform and Opening up, with the introduction and development of gradient theory, regional economics scholar, represented by Chen dongsheng, put forward the division of the three major economic belt ${ }^{3}$ of east, middle and west based on Chinese situation, which provides a good breakthrough point for national economic development strategy. In order to better analyze the changes in provincial investment climate in China, we have already discussed from the provincial perspective and cluster analysis in the first three parts of this article, further based on regional perspective, try to analyze the east, middle and west three economic zone as a starting point. According to Table 2, conclusions are as follows:

1) The investment climate patterns do not change but the overall improves.

From an overall perspective, the investment climate in China is that the East is still superior to the Central, in turn, the Central is better than the West. This situation is difficult to change in the short run. But with the penetration of the reform and opening up policy, China's economy runs smoothly. As is shown from the total amount of FDI, China holds the second highest usage rate of the foreign investment in developing country after the United States. Overall, due to the stable China's macro-economic growth rate maintains middle to high levels. In the meantime, foreign investment in China's comparative advantage still exists, basic economic and social development is getting better, the domestic market has huge potential.

2) Ranking of three municipalities in the East dropped.

By comparison, the investment environment ranking of Beijing, Shanghai, and Tianjin's appear backwards. Tianjin's ranking drops 3 seats only but from the first group to the second group. The three municipalities have similar causes. According to the 2011 blue book on China's urban competitiveness from the Chinese Academy of Social Sciences, Hong Kong, Shanghai and Beijing rank top 3 on the city competitiveness list. During 2007 and 2013 Shanghai maintains its high stability to attract foreign capital and actively develop new open areas. Due to the high position in Shanghai, the attraction of foreign investment improves from quantity focus to quality focus in the exploration of foreign education and training, maintenance of international business, foreign factoring, high-end manufacturing and other fields. These raise the threshold of foreign capital and prompt the relocation of low-end foreign industry. Similarly, Beijing, as the political center of China, China, also has certain level of restrictions on foreign investment.

According to Table 2 investment climate and Figure 1 clustering situation, Tianjin in the evaluation of investment climate in 2013 did not have outstanding score and lost its seat in the first group by sitting temporarily in the second group. Though the economic growth, Tianjin ranked first in 2010-2013, the economic growth had

\footnotetext{
${ }^{3}$ According to the standards of National Bureau of Statistics of China, China's three major economic zones include: the eastern economic zone: Beijing, Tianjin, Hebei, Liaoning, Shanghai, Jiangsu, Zhejiang, Fujian, Shandong, Guangdong and Hainan; the middle economic zone: Shanxi, Jilin, Heilongjiang, Anhui, Jiangxi, Henan, Hubei and Hunan; the western economic zone: Inner Mongolia, Guangxi, Chongqing, Sichuan, Guizhou, Yunnan, Tibet, Shanxi, Gansu, Qinghai, Ningxia and Xinjiang.
} 
Table 2. Scores and rankings of investment climate in 2007 and 2013 among 31 provincial level regions.

\begin{tabular}{|c|c|c|c|c|}
\hline \multirow[b]{2}{*}{ Province } & \multicolumn{2}{|l|}{2013} & \multicolumn{2}{|c|}{2007} \\
\hline & $\begin{array}{l}\text { Overall scores of investment } \\
\text { climate }\end{array}$ & Ranking & $\begin{array}{c}\text { Overall scores of } \\
\text { investment climate }\end{array}$ & Ranking \\
\hline Guangdong & 100 & 1 & 86 & 3 \\
\hline Jiangsu & 85.6 & 2 & 77 & 4 \\
\hline Shandong & 80.54 & 3 & 63 & 7 \\
\hline Zhejiang & 78.23 & 4 & 75 & 5 \\
\hline Beijing & 73.64 & 5 & 89 & 2 \\
\hline Shanghai & 72.9 & 6 & 100 & 1 \\
\hline Fujian & 58.87 & 7 & 56 & 8 \\
\hline Liaoning & 56.92 & 8 & 55 & 9 \\
\hline Tianjin & 55.24 & 9 & 69 & 6 \\
\hline Henan & 55.07 & 10 & 44 & 13 \\
\hline Anhui & 54.84 & 11 & 37 & 22 \\
\hline Sichuan & 53.81 & 12 & 47 & 10 \\
\hline Hunan & 53.41 & 13 & 42 & 14 \\
\hline Hebei & 51.46 & 14 & 47 & 11 \\
\hline Hubei & 51.32 & 15 & 46 & 12 \\
\hline Guangxi & 48.99 & 16 & 38 & 20 \\
\hline Chongqing & 48.2 & 17 & 40 & 17 \\
\hline Shaanxi & 46.23 & 18 & 35 & 25 \\
\hline Shanxi & 44.57 & 19 & 40 & 16 \\
\hline Jiangxi & 44.52 & 20 & 38 & 21 \\
\hline Heilongjiang & 41.91 & 21 & 39 & 19 \\
\hline Inner Mongolia & 40.45 & 22 & 41 & 15 \\
\hline Jilin & 39.08 & 23 & 39 & 18 \\
\hline Hainan & 38.44 & 24 & 35 & 24 \\
\hline Yunnan & 36.11 & 25 & 31 & 27 \\
\hline Guizhou & 33.68 & 26 & 26 & 30 \\
\hline Xinjiang & 33.05 & 27 & 36 & 23 \\
\hline Ningxia & 31.65 & 28 & 32 & 26 \\
\hline Gansu & 29.31 & 29 & 28 & 29 \\
\hline Qinghai & 23.43 & 30 & 29 & 28 \\
\hline
\end{tabular}

narrowed and appeared a downward trend. The main reason behind this phenomenon is its dominant heavy chemical industry in the industrial structure, the investment-oriented pulling strategy, the small portion of tertiary industry, light industry, and private small-medium enterprises. Since 2006, with the development of Binhai new area, a series of big projects and heavy investments settle in Tianjin. Upuntil now most of the large projects invested by Tianjin is in operation. Thus Tianjin is in the investment-driven to innovation-driven change and seeks a new positive turning point of the economic cycle.

3) The "low level equilibrium state" in the middle area is broken, and a rising potential is emerging.

Despite that the years from 2008 to 2013 have not seen subversive change to the structure of China's invest- 
ment climate, which, however, does not mean absence of revolutionary turn in investment climate of the three regions. For instance, in 2007, in the central region the top investment environment in Henan province scores only 7 points higher than the last one, Anhui province. In 2013, the ranking of Anhui province goes up to the second largest in the central area and Jilin province went to the lowest, score gap in central area expanding to 16 points. This means that some provinces break the original central low level equilibrium. Anhui Province is the best evidence. It improves the investment climate to a great extent through "strong industrial province" strategy, seizing the industrial transfer opportunities, and supportive national policy [11].

Secondly, it can be seen from Table 2, the top 10 provinces in investment climate in 2007 are all located in the eastern coastal areas, but by 2013, Henan, a central province, has to squeeze into the top ten list followed by Anhui. But this does not indicate the rise of central region. Total FDI annual inflow of funds among different regions in China can measure the levels of different regions in attracting foreign investment, indirectly reflects the size of the regional investment environment attractive to overseas investors. Comparing the gross FDI trends and the average FDI trends, it can be seen that since 2007 the total and the mean values of the actual usage of FDI are on the rise, among which the eastregion has the biggest increase and a slower increase in the middle and west region. From the total FDI amount perspective, the gap has not narrowed between the east and middle and the west but expanded; In terms of the mean value, the gap between the eastern and the central gap is relatively stable but an expansion gap appears between east and middle with the west. Therefore the "Central rise" and "Western Expansion" are still long path to go.

4) The west region generally advance slowly.

In recent years, in the preferential policy system, there are more "general privilege" and less "special privilege" and the west provinces have no distinct predominance in the competition of merchant and investment attracting. From the investment climate perspective, there is a gap between western regions and eastern coastal regions on government efficiency, transparency and the legal environment and it takes time to remedy. On the perspective of construction of the investment climate, the speed of infrastructure construction is slow, especially the level of county Industrial park is less than satisfactory. On the industry level [12], first of all, different from the east, leading industrial structure in the western region is basic industries presenting a high reliance on resources which is very different from the will of the foreign investors; secondly, the industrial capacity is weak. Local enterprises have insufficient capacity to match with the foreign investment and the investment cost for multinational companies is high.

\section{Conclusions and Policy Insights}

According to the result of cluster analysis and empirical analysis, we can find that in the past five years, the financial crisis has not caused the deterioration of investment climate in China, instead, improved wholly from the resource environment, economic environment, market environment, infrastructure and social environment. The spatial difference of China's investment climate is still very obvious, the bipolar structure still exists. The overall investment climate in the eastern part is superior to the central and western regions on the whole. Therefore, to further advance reform and opening up is still very necessary. At the same time, the competition within the three economic belts is still fierce: a good momentum of development in the central region, the gap is expected to narrow with the east and the middle, the west presents steady progress. Therefore, we propose the following suggestions to the three major economic belts:

Based on the analysis above, the investment environment ranking in the eastern region fluctuates but in generally far better than others and the introduction of FDI has dominant advantage. But in the long-term development perspective, the eastern region needs to insist on deepening the reform and opening up, make full use of the original economic foundation and geographical advantages, accelerate the development of advanced manufacturing and high-tech industries and participate in the competition with high value-added, high-tech products. Higher requirements are put forward on the introduction of FDI, which realize the promotion of quantity and quality. Making full use of the interactive function among the three urban agglomerations of Beijing-TianjinHebei, the Pearl river delta and the Yangtze river delta, promoting the regional investment climate.

In terms of the Midwest, despite the rise of some individual provinces in the middle, attracting FDI into is still a difficult problem and the industry factors are the leading causes. Central China should play a good geographical advantage of its adjacent to the eastern, continue to improve infrastructure, to establish a comprehensive external supporting conditions and investment soft environment, to seek actively to undertake the eastern coastal 
transfer of labor-intensive and resource-intensive industries, to accelerate the industrialization and urbanization. Secondly, the West China increases the intensity of industrial structure adjustment. While, local government should pay attention to get rid of the dependence on resources, promote industrial deepening processing. Attaching great importance to the cultivation of competitive advantage and turning comparative advantage into competitive advantage. "The silk road economic belt"4 will definitely expand opening up of the West, drive the development of the Midwest. The nine provinces preliminarily selected to "the silk road economic belt" should seize the opportunity to find out their advantages, identify the location, and lead to the prosperous economic development.

Please be aware that the cluster analysis is a kind of generality and static evaluation, thus the results are just for rough conclusion of the current investment climate in China, and the model itself has certain one-sidedness. Therefore, the future development trend of the provincial investment climate still needs in-depth analysis, according to their own conditions and the macroeconomic environment to put forward the corresponding measures to improve the investment climate.

\section{Funding}

Funding Project of Education Ministry for the Development of Liberal Arts and Social Sciences (12YJA790017); Planning Project of Guangdong Province Philosophy and Social Science (GD11CYJ03); jointly funded by 2015 Guangzhou Philosophy and Social Sciences Development “Twelve-five” Planning Issues (15Y12) and Guangdong industrial development and regional cooperation between Guangdong and Hong Kong Macao and Taiwan Research Center.

\section{References}

[1] Chen, L.S. (1995) An Analysis of the Investment Climate of Chinese Cities. Acta Geographica Sinica, No. 3, $240-247$.

[2] Pan, X. and Fan, D.C. (2007) Regional Investment Climate Evaluation Research. Inquiry into Economic Issues, No. 8, 40-45.

[3] Duan, X.M. (2006) An Analysis of the Investment Climate of Taiwanese Enterprises in Mainland China. World Economy Study, No. 2, 71-81.

[4] Liu, C.L. (2012) Japans Direct Investment to China: New Development, New Features and Countermeasures. Contemporary Economy of Japan, No. 1, 52-60.

[5] Zhou, C.S., et al. (2013) Changes of the Investment Climate in the Pearl River Delta Since Reform and Opening up in China. Tropical Geography, No. 9, 511-517.

[6] Ma, Y.M. (2014) Has China’s Investment Climate Deteriorated? Modern Bussiness, No. 6, 111-113.

[7] World Bank (2006) Governance, Investment Climate, and Harmonious Society: Competitiveness Enhancement for 120 Cities in China. No. 37759-CN.

[8] Taiwan Electrical and Electronics Industry Trade Association (2005) Research on Investment Climate and Risk in Chinese Mainland. 120-124.

[9] Chen, J. (2009) Fujian Province Investment Climate Monitoring and Evaluation Survey and Quality Inspection. Marketing Research, No. 3, 26-30.

[10] Wang, G.Y. (2010) Study on the Evaluation and Optimization of Investment Climate in Jiangxi Province. China Social Science Press, Beijing, 17-22.

[11] Tao, G.M. (2011) The Rise of the Central Region Strategy of Anhui Economic Development. Journal of Anhui Normal University (Natural Science), No. 9, 480-484.

[12] Yang, X.M. and Yuan, F. (2009) Why Didn’t FDI Move Westward? An Analysis Based on Industry Level. Economist, No. 3, 52-61.

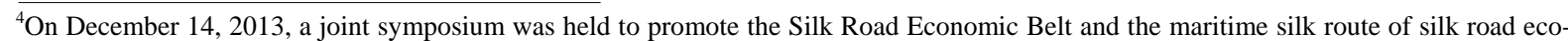
nomic zone by China's national development and reform commission and China's foreign ministry, provinces in China preliminary shortlisted for the silk road economic belt included five provinces in the northwest (Shanxi, Gansu, Ningxia, Qinghai, Xinjiang), four provinces and cities in the southwest (Sichuan, Chongqing, Yunnan, Guangxi) and five provinces in the east (Jiangsu, Zhejiang, Guangdong, Fujian, Hainan), 14 provinces in all.
} 